\title{
Health information and warnings on alcohol packaging in Ireland: it is time to progress the Public Health (Alcohol) Act 2018
}

\author{
Nathan Critchlow ${ }^{1,2}\left(\mathbb{D} \cdot\right.$ Crawford Moodie $^{1}\left(\mathbb{D} \cdot\right.$ Daniel Jones $^{1}(\mathrm{D}$
}

Received: 9 July 2021 / Accepted: 17 July 2021 / Published online: 28 July 2021

(c) Royal Academy of Medicine in Ireland 2021

Findings from the 2019-2020 Irish National Drug and Alcohol Survey are a reminder of the burden of alcohol-related harms in Ireland, with two-fifths of drinkers engaging in heavy episodic drinking at least once per month (six or more standard drinks on a single occasion) and $14.8 \%$ of the general population meeting the criteria for an alcohol use disorder [1]. This harmful use of alcohol is associated with myriad individual and societal harms and creates a substantial burden on Ireland's economy [2].

The packaging of alcoholic drinks provides a low-cost opportunity to communicate important health information to consumers, including at the point of purchase and before and during consumption. The World Health Organization (WHO) recommend alcohol companies be legally required to display relevant information (e.g., harms, consumption guidelines, warnings, nutritional value) on packaging and present it clearly and consistently across products [3]. Prominent on-pack warnings, which include images and provide clear information about use and harms, appear most likely to positively impact consumer behaviour [4-8].

Through the Public Health (Alcohol) Act 2018, Ireland already has a legal mechanism through which to enact the WHO's recommendations. Section 12 of the Act, as it will be referred to hereafter, will make it mandatory for the packaging of alcoholic drinks sold in Ireland to display: (i) a warning about the dangers of alcohol consumption (including when pregnant), (ii) a warning of the direct link between alcohol and fatal cancers, (iii) details of an independent website with public health information in relation to alcohol consumption, and (iv) nutritional information (e.g., grams of

Nathan Critchlow

nathan.critchlow@stir.ac.uk

1 Institute for Social Marketing and Health, Faculty of Health Sciences and Sport, University of Stirling, Stirling, Scotland

2 UK-Ireland Alcohol Research Network (ACORN), University of Stirling, Stirling, Scotland alcohol and energy content) [9]. The design and layout of this information will be specified by the state.

Several measures in the Act have already been implemented (e.g., structural separation of alcoholic drinks in retailers and a ban on some outdoor advertising) or will be soon (e.g., minimum pricing per gram of alcohol or a ban on sponsorship of certain events). As far as we are aware, however, there is no scheduled commencement date for Sect. 12, the provisions on alcohol product labelling. The Food Safety Authority of Ireland (FSAI) held a consultation, which closed in late 2019, to help inform implementation of this labelling measure [10], but the responses and any resulting actions are not yet known.

Non-commencement of the provisions on mandatory labelling prolongs reliance on self-regulatory designs and presentation of this information to the public. There are some practical benefits to self-regulation, for example negating the time and resource burden associated with legislative action. Such approaches, however, have been criticised for omitting important health information, lacking clarity, and having limited effectiveness [5, 7, 11, 12]. A study of 21 European countries found that Ireland was one of only two where alcohol consumption had not declined during the first stages of the COVID-19 pandemic [13]. That on-trade premises were closed or had restricted access for much of this time, while off-trade sales were permitted, suggest an increase in home consumption during this period. That the mandatory labelling provisions are not yet in force means an opportunity to maximise exposure to new warnings on take-home packaging has already been missed.

There are several reasons why Ireland's Government may wish to accelerate progress of Sect. 12. First, since the Act was passed and the FSAI consultation closed, there has been positive evaluation concerning the real-world impact of warnings on the packaging of alcoholic drinks in a Canadian territory [e.g., 14-17] and further evidence of the potential public health impact in the United Kingdom (UK) [e.g., $5,6]$. Second, research suggests that stronger labelling is 
supported by the public [18], including in Ireland [19], and that increased awareness of the health impacts of alcohol may increase public support for other alcohol control policies [20]. Third, the tobacco and wider warning literature offers a template on how best to design warnings [21, 22], and the efficacy of well-designed warnings on tobacco products [21,23] provides insight into their potential impact for alcoholic drinks.

On-pack warnings that inform consumers of the potential harms associated with alcohol consumption are opposed by the alcohol industry [24] and will likely be legally challenged [25]. This may be viewed as a barrier, but litigation is the norm in the tobacco field, with tobacco companies seldom successful. Indeed, despite legal challenges to tobacco packaging policies in many continents, over 100 countries now have large pictorial warnings (that cover at least 50\% of the main display areas on tobacco packs) and a growing number of countries require standardised packaging [26]; Ireland, as a global leader in tobacco control, requires both [27].

While the implementation and planned rollout of several components of the Act may help to better safeguard the public-although evaluation is needed to understand whether this is the case-consumers have a basic right to be properly informed about the possible harms of products available for purchase [3]. This is currently not the case for alcoholic drinks in Ireland. Strong political leadership was key to the passage of the Act [28] and will likely be needed to advance Sect. 12 if this policy is to fulfil its intended purpose.

Acknowledgements The authors thank SG for providing images of current alcohol packaging and labelling in Ireland, which helped inform this manuscript.

Author contribution Conceptualisation, N.C., C.M.; Writing-Original draft, N.C.; Writing—Review and editing, N.C., C.M., D.J. All authors have read and agreed to the published version of manuscript.

Funding NC is funded through an academic fellowship from the Society for the Study of Addiction (SSA) (WT ID: 1574045). CM and DJ received no funding in relation to this manuscript.

Data availability There are no data or materials associated with contribution.

\section{Declarations}

Ethics approval This article does not contain any studies with human participants or animals performed by any of the authors.

Conflict of interests NC is on the board of directors at Alcohol Focus Scotland. NC has received unrelated funding from the Institute of Public Health in Ireland to support his fellowship research examining implementation of the Public Health (Alcohol) Act, but this funding does not relate to the legislative controls concerning the labelling of alcoholic drinks. NC has previously received unrelated funding from Cancer Research UK to examine adolescents' recall of information and health messaging on alcohol packaging. NC is a co-investigator on the UK-Ireland Alcohol Research Network (ACORN), which is jointly funded by the UK's Economic and Social Research Council and the Irish Research Council. CM and DJ have received unrelated funding from Alcohol Focus Scotland for research exploring drinkers' response to health information and warnings on alcohol packaging. DJ has previously received a PhD studentship from the University of Stirling to examine consumer reactions to alcohol packaging and labelling.

\section{References}

1. Mongan D, Millar SR, Galvin B (2021) The 2019-20 Irish national drug and alcohol survey: Main findings. Health Research Board, Dublin

2. O'Dwyer C, Mongan D, Doyle A et al (2021) Alcohol consumption, alcohol-related harm, and alcohol policy in Ireland (HRB Overview, Series 11). Health Research Board, Dublin

3. Jane-Llopis E, Kokole D, Neufield M et al (2020) What is the current alcohol labelling practice in the WHO European Region and what are the barriers and facilitators to development and implementation of alcohol labelling policy? (WHO Health Evidence Network Series, Report 68). World Health Organization European Office, Copenhagen

4. Dimova ED, Mitchell D (2021) Rapid literature review on the impact of health messaging and product information on alcohol labelling. Drugs. https://doi.org/10.1080/09687637.2021.1932754

5. Jones D, Moodie C, Purves RI et al (2021) Health information, messaging, and warnings on alcohol packaging: a focus group study with young adult drinkers in Scotland. Addict Res Theory. https://doi.org/10.1080/16066359.2021.1884229

6. Clarke N, Pechey E, Mantzari E et al (2021) Impact of health warning labels communicating the risk of cancer on alcohol selection: an online experimental study. Addiction 116(1):41-52. https://doi.org/10.1111/add.15072

7. Blackwell AKM, Drax K, Attwood AS et al (2018) Informing drinkers: can current UK alcohol labels be improved? Drug Alcohol Depend 192:163-170. https://doi.org/10.1016/j.drugalcdep. 2018.07.032

8. Sillero-Rejon C, Attwood AS, Blackwell AKM et al (2018) Alcohol pictorial health warning labels: the impact of self-affirmation and health warning severity. BMC Public Health 18:1403. https:// doi.org/10.1186/s12889-018-6243-6

9. Oireachtas (2018) Public Health (Alcohol) Act 2018 (Number 24 of 2018). Oireachtas, Dublin

10. Food Safety Authority of Ireland (2019) Public consultation in respect of regulations to made under sections 12 and 13 of the Public Health (Alcohol) Act 2018. Food Safety Authority of Ireland. https://www.fsai.ie/uploadedFiles/Legislation/Consultations/ info_note_Public_Health_Alcohol_Act.pdf

11. Petticrew M, Douglas N, Knai C et al (2016) Health information on alcoholic beverage containers: has the alcohol industry's pledge in England to improve labelling been met? Addiction 111(1):51-55. https://doi.org/10.1111/add.13094

12. O'Brien P, Stockwell T, Vallace K et al (2021) WHO should not support alcohol industry co-regulation of public health labelling. Addiction 116(7):1619-1621. https://doi.org/10.1111/add.15462

13. Kilian C, Rehm J, Alleback P et al (2021) Alcohol consumption during the COVID-19 pandemic in Europe: a large-scale crosssectional study in 21 countries. Addiction. https://doi.org/10.1111/ add 15530 
14. Zhao J, Stockwell T, Vallance K et al (2020) The effects of alcohol warning labels on population alcohol consumption: an interrupted time series analysis of alcohol sales in Yukon. Canada J Stud Alcohol Drugs 81(2):225-237. https://doi.org/10.15288/jsad. 2020.81.225

15. Hobin E, Weerasinghe A, Vallance $\mathrm{K}$ et al (2020) Testing alcohol labels as a tool to communicate cancer risk to drinkers: a realworld quasi-experimental study. J Stud Alcohol Drugs 81(2):249_ 261. https://doi.org/10.15288/jsad.2020.81.249

16. Schoueri-Mychasiw WA, Weerasinghe A, Vallance K et al (2020) Examining the impact of alcohol labels on awareness and knowledge of national drinking guidelines: a real-world study in Yukon. Canada J Stud Alcohol Drugs 81(2):262-272. https://doi.org/10. 15288/jsad.2020.81.262

17. Schoueri-Mychasiw WA, Weerasinghe A, Stockwell T et al (2021) Use as directed: do standard drink labels on alcohol containers help consumers drink (ir)responsibly? Real-world evidence from a quasi-experimental study in Yukon. Canada Drug Alcohol Rev 40(2):247-257. https://doi.org/10.1111/dar.13165

18. Martin-Moreno JM, Harris ME, Breda J et al (2013) Enhanced labelling on alcoholic drinks: reviewing the evidence to guide alcohol policy. Eur J Public Health 23(6):1082-1087. https://doi. org/10.1093/eurpub/ckt046

19. Wilkinson C, Room R (2009) Warnings on alcohol containers and advertisements: international experience and evidence on effects. Drug Alcohol Rev 28(4):426-435. https://doi.org/10.1111/j.14653362.2009.00055.x

20. Bates S, Holmes J, Gavens L et al (2018) Awareness of alcohol as a risk factor for cancer is associated with public support for alcohol policies. BMC Public Health 118:668. https://doi.org/10. 1186/s12889-018-5581-8
21. Noar SM, Frances DB, Bridges C et al (2017) Effects of strengthening cigarette pack warnings on attention and message processing: a systematic review. Journal Mass Commun Q 94(2):416442. https://doi.org/10.1177/1077699016674188

22. Wogalter MS, Conzola VC, Smith-Jackson TL (2002) Researchbased guidelines for warning design and evaluation. Appl Ergon 33(3):219-230. https://doi.org/10.1016/s0003-6870(02)00009-1

23. Moodie C, Best C, Lund I et al (2021) The response of smokers to health warnings on packs in the United Kingdom and Norway following the introduction of standardised packaging. Nicotine Tob Res. https://doi.org/10.1093/ntr/ntab027

24. Vallance K, Vincent A, Schoueri-Mychasiw N et al (2020) News media and the influence of the alcohol industry: an analysis of media coverage of alcohol warning labels with a cancer message in Canada and Ireland. J Stud Alcohol Drugs 81(2):273-283. https://doi.org/10.15288/jsad.2020.81.273

25. O'Brien P, Gleeson D, Room R et al (2018) Commentary on 'Communicating messages about drinking': using the 'Big legal guns' to block alcohol health warning labels. Alcohol 53(3):333336. https://doi.org/10.1093/alcalc/agx124

26. Canadian Cancer Society (2018) Cigarette package health warnings: international status report. Canadian Cancer Society. http:// www.fctc.org/wp-content/uploads/2018/10/CCS-internationalwarnings-report-2018-English-2-MB.pdf

27. Heath Service Executive (2018) The state of tobacco control in Ireland: HSE Tobacco Free Ireland Programme, 2018. Health Service Executive, Dublin

28. Lesch M, McCambrdige J (2021) Waiting for the wave: political leadership, policy windows, and alcohol policy change in Ireland. Soc Sci Med 282:114116. https://doi.org/10.1016/j.socscimed. 2021.114116 